\title{
Production of Pyrolysis Oil with Low Bromine and Antimony Contents from Plastic Material Containing Brominated Flame Retardants and Antimony Trioxide
}

\author{
$\mathrm{Hu} \mathrm{Wu}^{1}$, Yafei Shen ${ }^{1}$, Noboru Harada ${ }^{1}$, Qi $\mathrm{An}^{1} \&$ Kunio Yoshikawa ${ }^{1}$ \\ ${ }^{1}$ Department of Environmental Science and Technology, Tokyo Institute of Technology, Yokohama, Japan \\ Correspondence: Hu Wu, Department of Environmental Science and Technology, Tokyo Institute of Technology, \\ Yokohama, Japan. Tel: 81-45-924-5507. E-mail: wuhu2010wuhu@gmail.com
}

Received: October 7, 2014 Accepted: October 20, 2014 Online Published: November 9, 2014

doi:10.5539/eer.v4n3p105 URL: http://dx.doi.org/10.5539/eer.v4n3p105

\begin{abstract}
Thermal degradation of high impact polystyrene (HIPS) containing brominated flame retardants and antimony trioxide $\left(\mathrm{Sb}_{2} \mathrm{O}_{3}\right)$ was conducted at different temperatures with the presence of various additives (red mud, limestone and natural zeolite) in a fixed-bed reactor. The effect of the pyrolysis temperature on the product yield and the bromine content in the oil product was investigated. It was found that the maximum oil yield ( 84.38 wt.\%) was obtained at the pyrolysis temperature of $500{ }^{\circ} \mathrm{C}$. The pyrolysis temperature had no significant impact on the bromine reduction in the oil products. The bromine in the flame retardant was mainly transferred into the oil products, where the bromine content was in the range of 7.96-8.56 wt.\%. With the aim of removing bromine and antimony from the oils, three additives (red mud, limestone and natural zeolite) was used to investigate the influence on the product yield and composition, especially on the bromine and antimony removal ability from the oil products. In this study, it was found that all of the additives could significantly lower the bromine and antimony content in the oils and the red mud was the most effective. The presence of red mud could reduce the bromine and antimony content from 8.21 and $1.84 \mathrm{wt} . \%$ when no additive was employed to 0.84 and $0.35 \mathrm{wt} . \%$, respectively. In addition, the distribution and fate of bromine and antimony in the residues were also studied by the SEM-EDX and XRD analysis in detail.
\end{abstract}

Keywords: E-waste plastic, $\mathrm{Br}$-HIPS, $\mathrm{Sb}_{2} \mathrm{O}_{3}$-synergist, catalytic pyrolysis, debromination, fuel oil

\section{Introduction}

Waste electrical and electronic equipment (WEEE) are currently considered to be one of the fastest growing solid waste streams in the world. According to a report of UNEP (2009) about the recycling from WEEE to resources, 40 million tons of WEEE were generated and discharged annually in the world and it was expected an alarming growth per year in the future (United Nations Environment Programme, 2009). It was well known that there are lots of valuable metals and plastics contained in WEEE, which are worthy recyclable feedstock and could be converted into important mineral resources, fuel and chemical feedstock if recycled scientifically. On the other hand, WEEE also contained certain dangerous and hazardous substances, such as toxic metals and brominated flame retardants, which will pose considerable environmental pollution and health risks if treated inadequately (Yang, Sun, Xiang, Hu \& Su, 2013; Ongondo, Williams \& Cherrett, 2011). Therefore, how to scientifically and cost-effectively reuse, recycle and recover WEEE has drawn plenty of attentions through the world.

WEEE plastics, which account for about $30 \%$ of the total weight of WEEE, are worthwhile recyclable parts of WEEE (Yang et al, 2013). One of the most popular plastics widely used in electrical and electronic equipment (EEE) is high-impact polystyrene (HIPS), because of its low cost and excellent impact resistance and machinability properties. HIPS is a composite material composed of a polystyrene phase and a dispersed polybutadiene rubber phase (Bhaskar et al, 2003). Polybrominated compounds and antimony trioxide $\left(\mathrm{Sb}_{2} \mathrm{O}_{3}\right)$, as synergistic flame retardants, are frequently added to HIPS to reduce its flammability (Jakab, Uddin, Bhaskar \& Sakata, 2003). Because of the presence of brominated flame retardants (BFRs), the traditional methods of dealing with WEEE plastics, such as land-filling and incineration, will produce secondary pollution on the ecological environment and endanger human health as well as being a waste of resource (Yang et al, 2013). For instance, the direct incineration of WEEE plastics containing brominated flame retardant will produce some 
highly toxic brominated dioxins and dibenzofurans ( $\mathrm{Ni}$ et al, 2012). With a view to the environmental protection and saving non-regeneration resources, feedstock recycling technologies have been proposed as a viable processing route for converting WEEE plastics into useful fuels and chemical feedstock.

The pyrolysis and the catalytic pyrolysis are the most widely used feedstock recycling technologies for the conversion of WEEE plastics into valuable chemicals and fuel oil. Because of its low cost and easy operation, pyrolysis used for recycling WEEE plastics have been intensively investigated under different feedstocks, operation conditions, reactors, and increasing temperature stages (Yang et al, 2013). However, there were lots of organic brominated compounds remaining in the pyrolysis oils, which would reduce the quality and hinder the reuse of them. Compared with the thermal pyrolysis, the catalytic pyrolysis not only reduces the degradation temperature, but also obtains comparatively high-grade oil fuel without bromine. A wide range of catalysts have been tested for upgrading the quality and debromination of the pyrolysis oil derived from WEEE plastics and brominated flame retardants, such as zeolites (Hall \& Williams, 2008; Bozi \& Blazsó, 2009), FCC catalysts (Hall, Miskolczi, Onwudili \& Williams, 2008), metallic oxides (Jung, S. Kim \& J. Kim, 2012; Terakado, Ohhashi \& Hirasawa, 2011; Terakado, Ohhashi \& Hirasawa, 2013), etc. For example, Hall and Williams (2008) investigated the catalytic pyrolysis of brominated flame-retarded HIPS and ABS by using HY Zeolite and HZSM-5 Zeolite, which could effectively remove the organobromines from the pyrolysis products. Terakado and Hirasawa (2011; 2013) used the metal oxides in the pyrolysis of TBBPA and printed circuit boards including brominated flame retardants, respectively. They concluded that the addition of metal oxides could suppress the formation of $\mathrm{HBr}$ and brominated organic compounds.

However, from a practical industrial application point of view, the use of expensive catalysts, such as commercial HY and HZSM-5 zeolites, would increase the operation cost, due to a large amounts of catalyst demand and the deactivation of catalysts in a large continuously operating plant. Ali et al. (2002) indicated that the main factor is the catalyst cost for the economic comparison of catalytic cracking and thermal cracking technologies. In addition, Cardona et al. (2000) concluded that a plastic waste pyrolysis process could only be supported if the catalyst cost was practically zero (Lópeza et al, 2011). Therefore, it is necessary to develop the low-cost catalysts or additives for pyrolysis of WEEE plastic and debromination of brominated flame retardant.

Red mud, a solid waste product of the bauxite processing through the Bayer process, is mainly composed of $\mathrm{Fe}_{2} \mathrm{O}_{3}, \mathrm{Al}_{2} \mathrm{O}_{3}, \mathrm{SiO}_{2}$ and $\mathrm{TiO}_{2}$. Because of its special physicochemical properties, such as a high content of $\mathrm{Fe}_{2} \mathrm{O}_{3}$, a high surface area, the sintering resistance and a low cost, red mud have been used as catalysts for the hydrodechlorination and hydrogenation reactions (Sushil \& Batra, 2008; Ordóñez, Sastre \& Deíz, 2001; Álvarez, Ordóñez, Rosal, Sastre \& Díez, 1999). In addition, it was found that, in the presence of $\mathrm{Al}_{2} \mathrm{O}_{3}, \mathrm{SiO}_{2}$ and $\mathrm{TiO}_{2}$, the red mud with some acidity could contribute to the catalytic cracking of plastic wastes (Lópeza et al, 2011). Limestone, as a common natural mineral, was also widely employed as a catalyst or an additive in the pyrolysis and gasification of biomass and plastic for the dehalogenation and tar removal (Hinz et al, 1994; Jung et al, 2012). The natural zeolite was also widely studied as catalysts for the catalytic pyrolysis of biomass and plastic to upgrade the liquid product due to its large surface area, acidity and sintering resistance property (Lee, Yoon, Kim \& Park, 2002; Lee, Yoon, Kim \& Park, 2001).

To our knowledge, there were few reported works on the use of red mud, limestone and natural zeolite for the WEEE plastic pyrolysis (Yanika, Uddinb, Ikeuchib \& Sakata, 2001; Vasile et al, 2008). In this study, thermal degradation of HIPS containing BFRs and $\mathrm{Sb}_{2} \mathrm{O}_{3}$ was carried out at different temperatures with the presence of three additives (red mud, limestone and natural zeolite) in a fixed-bed reactor. The influence of the pyrolysis temperature on the product yield and bromine distribution in the oil products was evaluated systematically. In addition, the effect of three additives (red mud, limestone and natural zeolite) on the yields and compositions of products were investigated in details. Furthermore, the special attention was paid to study the content and distribution of bromine and antimony in the oils and residues, respectively, when the additives were used.

\section{Experimental}

\subsection{Materials}

The feedstock sample was high-impact polystyrene containing brominated flame retardant and antimony trioxide as a synergist, which was supplied by the PS Japan Corporation, Japan. The sample will be referred to as Br-HIPS. In order to mix the Br-HIPS sample with an additive uniformly, the pellet-type Br-HIPS sample was ground and sieved to obtain the powder Br-HIPS sample with a diameter smaller than $0.5 \mathrm{~mm}$. The proximate analysis and ultimate analysis of the Br-HIPS sample was presented in Table 1. 
Table 1. Proximate analysis and ultimate analysis of the Br-HIPS sample

\begin{tabular}{lccc}
\hline Proximate analysis & wt.\% & Ultimate analysis & wt.\% \\
\hline Moisture & 0.00 & $\mathrm{C}$ & 78.61 \\
Volatile matter & 98.13 & $\mathrm{H}$ & 7.11 \\
Fixed carbon & 0.34 & $\mathrm{O}$ & 0.75 \\
Ash & 1.53 & $\mathrm{~N}$ & 0.10 \\
& & $\mathrm{Br}$ & 9.30 \\
& & $\mathrm{Sb}$ & 3.77 \\
& & $\mathrm{Ti}$ & 0.36 \\
\hline
\end{tabular}

The additives employed in this study were red mud, natural zeolite and limestone, which were obtained from the local company of Indonesia. Before the experiments, three additives were ground, sieved and then dried at $110{ }^{\circ} \mathrm{C}$ over the night. The red mud and natural was calcined at $500{ }^{\circ} \mathrm{C}$ for 2 hours to remove the organic impurities while the natural limestone was calcined at $900{ }^{\circ} \mathrm{C}$ for 4 hours to obtain $\mathrm{CaO}$ from the limestone. There were no any other activation operations for calcined red mud, natural zeolite and limestone. The additives will be referred to as RM, NZ and CL, respectively. Their chemical components and BET surface area are shown in Table 2.

Table 2. Chemical components and BET surface area of RM, NZ and CL (wt.\%) (dry basis)

\begin{tabular}{lccccccccc}
\hline Additives & $\mathrm{Fe}_{2} \mathrm{O}_{3}$ & $\mathrm{SiO}_{2}$ & $\mathrm{Al}_{2} \mathrm{O}_{3}$ & $\mathrm{CaO}$ & $\mathrm{TiO}_{2}$ & $\mathrm{Na}_{2} \mathrm{O}$ & $\mathrm{MgO}$ & Others & $\begin{array}{c}\mathrm{BET} \text { surface area } \\
\left(\mathrm{m}^{2} / \mathrm{g}\right)\end{array}$ \\
\hline Red Mud & 51.30 & 13.00 & 13.90 & 3.31 & 10.40 & 4.93 & 0.00 & 3.16 & 21.26 \\
Calcined Limestone & 0.00 & 0.97 & 0.42 & 97.60 & 0.00 & 0.00 & 0.32 & 0.69 & 7.49 \\
Natural Zeolite & 3.58 & 77.30 & 9.62 & 5.32 & 0.64 & 0.69 & 0.00 & 2.85 & 60.16 \\
\hline
\end{tabular}

${ }^{\mathrm{a}}$ By difference.

\subsection{Experimental Setup}

Fig. 1 is the schematic diagram of the experimental apparatus. The pyrolysis reactor was made of quartz. The inner diameter and inner height were $50 \mathrm{~mm}$ and $280 \mathrm{~mm}$, respectively. In the thermal pyrolysis experiments without additives, the powder sample was fed into the reactor and was pyrolyzed over a range of temperature $\left(450-550{ }^{\circ} \mathrm{C}\right.$ ) under the carrier gas of $\mathrm{N}_{2}$ with a flow rate of $50 \mathrm{ml} / \mathrm{min}$. When the additives were used, $40 \mathrm{~g}$ samples and $8 \mathrm{~g}$ of each additive ( $20 \mathrm{wt} . \%)$ were mixed well, respectively, and fed into the reactor, which was heated to $500{ }^{\circ} \mathrm{C}$ at a heating rate of $50{ }^{\circ} \mathrm{C} / \mathrm{min}$. In the all experiments, after the reactor temperature reached the target temperature, it was held at this temperature for 2 hours and was then cooled quickly. The oil product was condensed in an oil collector, which was cooled by dry ice and ethanol mixture solution. In order to capture $\mathrm{HBr}$, the gaseous products were scrubbed with $1 \mathrm{~mol} / \mathrm{L} \mathrm{NaOH}$ solution in the second trap before being collected in a tedlar bag. The every part was connected by silicon tubes. 


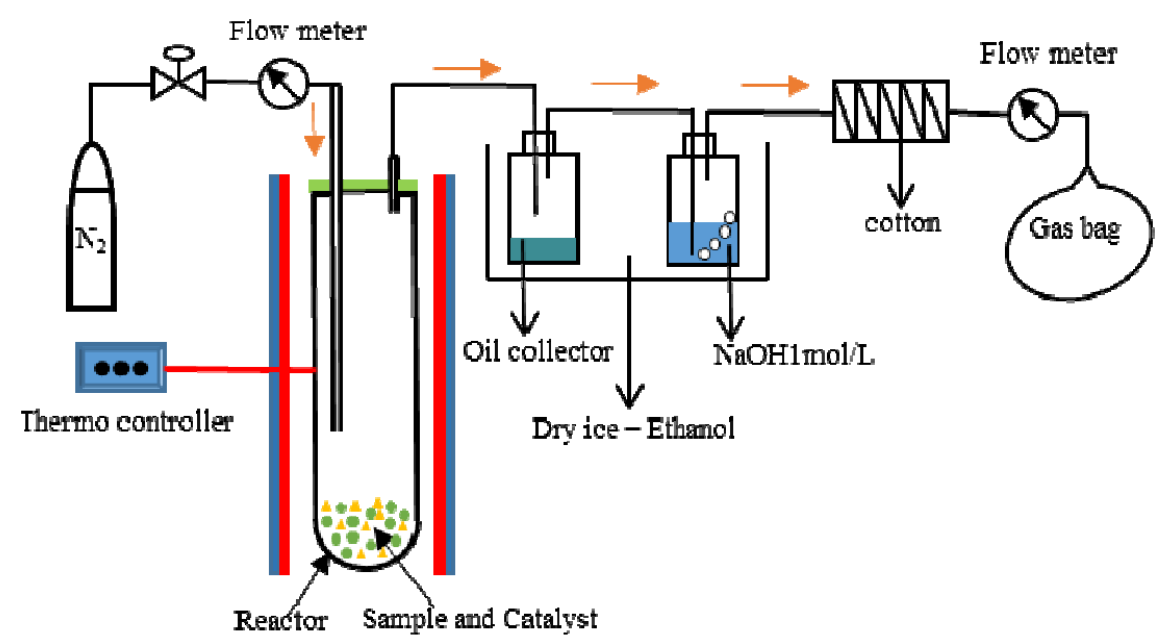

Fig. 1. Schematic diagram of the pyrolysis apparatus

\subsection{Analytical Methods}

The CHN element analysis was conducted by using a Micro Corder JM 10 Elemental Analyzer. The bromine contents of the sample and the pyrolysis oils were determined by using an air combustor coupled with Dionex ICS-1100 ion chromatography fitted with a Shodex IC S1-904E column according to JIS K 7392. The amount of antimony in the Br-HIPS sample and the oil products were determined by the inductively coupled plasma mass spectrometry (ICP-MS). The solution for the ICP-MS analysis was prepared by digesting $10 \mathrm{mg}$ of sample or product in the mixed concentrated nitric and sulfuric acid in a sonicator for 3 hours in $200{ }^{\circ} \mathrm{C}$. After digestion, the solution was diluted with distilled water to $50 \mathrm{ml}$ for the ICP-MS analysis. The antimony and bromine contents in the pyrolysis residues were measured by a scanning electron microscopy with energy disperse X-ray analysis (SEM-EDX).

The chemical compositions of the catalysts were determined by an energy dispersive X-ray fluorescence spectrometer (XRF) under vacuum mode for precise measurement. A powder X-ray diffraction (XRD) analysis was carried out for the verification of the crystallinity of the fresh additives and used additives. XRD measurements were performed using a Rigaku Ultimal V diffractometer with the $\mathrm{CuK} \alpha$ radiation $(\lambda=1.540)$ at $40 \mathrm{kV}$ and $40 \mathrm{~mA}$. The XRD patterns were accumulated in the range of $5-80^{\circ}$ every $0.02^{\circ}(2 \theta)$ with the counting time of $1 \mathrm{~s}$ per step. The XRD patterns of three additives were presented in Fig. 2. The surface structure property was analyzed by the SEM. Surface area and textural properties of the used catalysts were determined by $\mathrm{N}_{2}$ physical adsorption at $77 \mathrm{~K}$, applying the Brunauer-Emmett-Teller (BET) method, using a Micromeritics Tristar 3020 equipment.

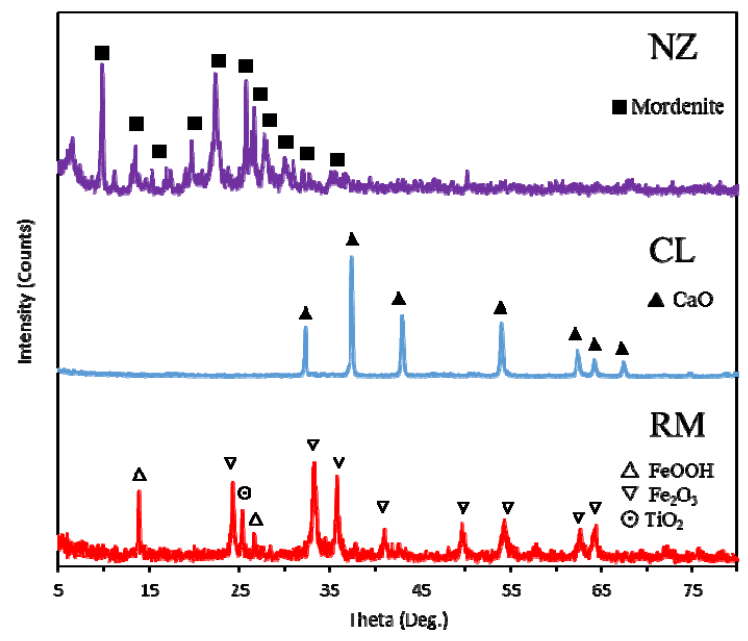

Fig. 2. The XRD patterns of RM, CL and RM 
The yield of the oil product was measured by the weight difference of the silicon tube and the oil collector after and before the experiments. The yield of the solid product was determined by the weight difference of the reactor after and before the experiments. The yield of the gas product was calculated by subtracting the weight of the solid and oil products from the total weight of the sample.

The composition of the oil product was analyzed by a gas chromatograph coupled with a mass spectrometer (GC-MS) (Agilent 6890N, GC-MSD 5973N). The column was an HP5 (5\% Ph-Me-Siloxane) capillary column, $30 \mathrm{~m}$ length with $0.25 \mathrm{~mm}$ diameter and $0.25 \mu \mathrm{m}$ film thickness. Helium was used as the carrier gas. The injector temperature was $250{ }^{\circ} \mathrm{C}$. The temperature program used was the initial temperature of $40{ }^{\circ} \mathrm{C}$ for 10 minutes followed by the heating rate of $5{ }^{\circ} \mathrm{C} / \mathrm{min}$ to $300{ }^{\circ} \mathrm{C}$ and held at $300{ }^{\circ} \mathrm{C}$ for 20 minutes. The ion source and Quadrupole temperatures were $230^{\circ} \mathrm{C}$ and $150{ }^{\circ} \mathrm{C}$, respectively. The organobrominated compound in the oil products were measured by the gas chromatograph fitted with electron capture detectors (GC-ECD). In addition, the liquid pyrolysis products were further characterized using Fourier Transform Infrared Spectroscopy (FT-IR) with a JIR-SPX200 FT-IR spectrometer. The oil samples were mixed with $\mathrm{KBr}$ and pelletized. Then, it was scanned from 400 to $4000 \mathrm{~cm}^{-1}$ with the resolution of $4 \mathrm{~cm}^{-1}$.

The composition of the produced gases in the experiments was measured by a micro gas chromatograph fitted with a thermal conductivity detector (GC-TCD) (Agilent Micro 3000), and the yield of each component was calculated by the following equation.

$$
m_{i}=M_{i} \times \frac{C_{i}}{C_{N_{2}}} \times \frac{V_{N_{2}}}{22.4}
$$

Where $m_{i}=$ the yield of each gas product, $M_{i}=$ the molar mass of each gas product; $C_{i}$, the concentration of the gas $i$ in the gas products; $C_{N_{2}}=$ the concentration of $N_{2}$ in the gas products; $V_{N_{2}}=N_{2}$ volume $=$ the $N_{2}$ flow rate $\times$ the flow time.

\section{Results and Discussion}

\subsection{TGA Results}

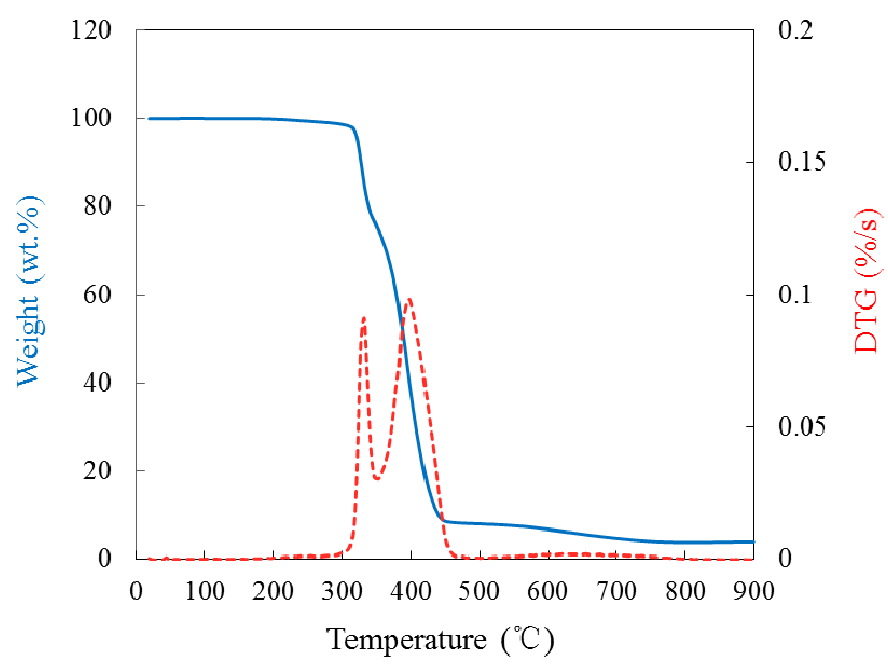

Fig. 3. TGA and DTG curve of $\mathrm{Br}-\mathrm{HIPS}$ at $5^{\circ} \mathrm{C} / \mathrm{min}$

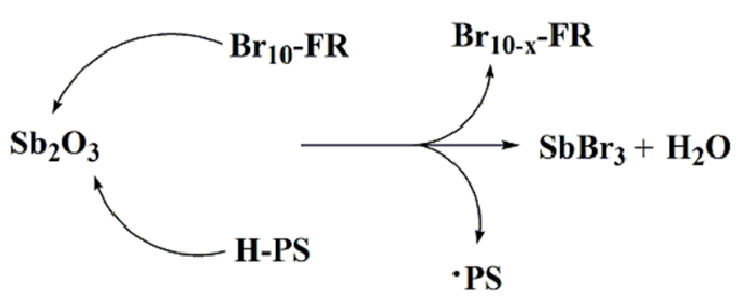

Fig. 4. First-stage degradation mechanism of Br-HIPS proposed by Bhaskar et al. (2003) 
In order to investigate the thermal decomposition property of Br-HIPS, the thermogravimetric analysis (TGA) was conducted with a thermogravimetric analyzer (Shimadzu D50). $10 \mathrm{mg}$ of HIPS-Br sample was loaded into the alumina crucible and heated from the ambient temperature to $900{ }^{\circ} \mathrm{C}$ with a heating rate of $5{ }^{\circ} \mathrm{C} / \mathrm{min}$. The flow rate of the carrier gas $\left(\mathrm{N}_{2}\right)$ was $150 \mathrm{~mL} / \mathrm{min}$. The TGA and DTG curves of Br-HIPS were shown in Fig. 3. The TGA curves indicated that the decomposition of Br-HIPS mainly occurred between 310 and $450{ }^{\circ} \mathrm{C}$, followed by a stable mass reduction at higher temperatures. The DTG curve obviously illustrated that the pyrolysis of Br-HIPS mainly included two distinct decomposition stages from 310 to $350{ }^{\circ} \mathrm{C}$ and from 360 to $450^{\circ} \mathrm{C}$, respectively. This result corresponds to the previous reported works (Bhaskar et al, 2003; Jung et al, 2012) that the first decomposition stage was attributed to the presence of $\mathrm{Sb}_{2} \mathrm{O}_{3}$ as a synergist, which will reacted with BFRs and partial polystyrene by the dehydrogenation and debromination reactions, as presented in Fig. 4. The decomposition of the majority of Br-HIPS took place in the second stage by the $\beta$-scission reaction (Lee et al, 2001). Furthermore, the Br-HIPS pyrolysis residues were about 7 wt. $\%$ and 2 wt. $\%$ at 600 and $900{ }^{\circ} \mathrm{C}$, respectively, which indicated that the remaining residue could be further decomposed at a higher temperature. These thermogravimetric analysis results could be used for determining the suitable pyrolysis temperatures for the following experiments in the fixed bed reactor.

\subsection{Effect of the Pyrolysis Temperature on the Product Yields and the Bromine Content in the Produced Oils}

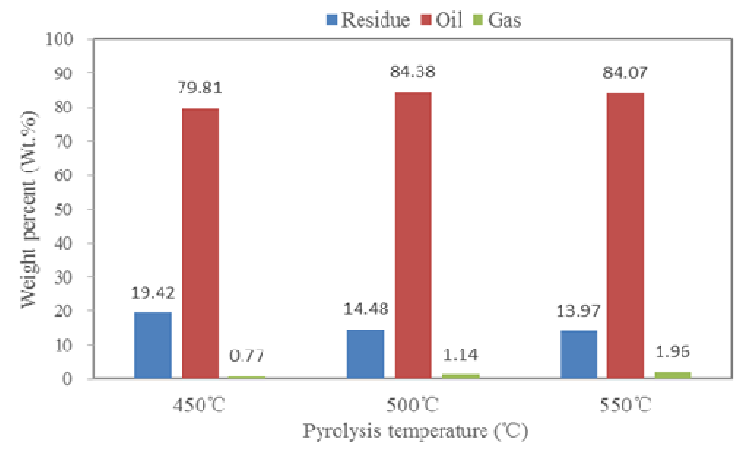

Fig. 5. Effect of the pyrolysis temperature on the product yield

It is well known that the reaction temperature is an essential parameter for both the plastic pyrolysis degradation and the catalyst activation (Park, Kang \& Kim, 2008). Therefore, a preliminary study of Br-HIPS pyrolysis at different temperatures was conducted in an attempt to investigate the impact of the pyrolysis temperature on the product yield and the bromine content in the oil products. The effect of the pyrolysis temperature on the product yield is shown in Fig. 5. It indicated that as the increasing of the pyrolysis temperature from $450^{\circ} \mathrm{C}$ to $500^{\circ} \mathrm{C}$, the yield of the oil and gaseous products increased, accompanied by the decrease of the yield of the solid residue, which was attributed to the intense cracking of Br-HIPS under the higher pyrolysis temperature resulting in a higher conversion ratio of samples into the gaseous and liquid products (Aguado, Serrano, Miguel, Castro \& Madrid, 2007; Syamsiro et al, 2013). When the pyrolysis temperature increased from $500^{\circ} \mathrm{C}$ to $550^{\circ} \mathrm{C}$, the yield of the gaseous product increased at the expense of the liquid product and the solid residue, which implied that a higher pyrolysis temperature would further convert some liquid products into small-molecular gaseous products. However, the change was slight, which indicated that the pyrolysis temperature of $500^{\circ} \mathrm{C}$ was high enough for the thermal degradation of Br-HIPS. The maximum oil product yield $(84.4 \mathrm{wt}$. \%) was obtained at the pyrolysis temperature of $500^{\circ} \mathrm{C}$.

The total bromine content in the pyrolysis oils was measured using a bomb calorimeter equipped with an ion chromatograph (JIS K 7392), and the result is shown in Table 3. This result clearly shows that there was a high bromine content in each oil product, which means large amounts of bromine was transferred to the oil products during the pyrolysis of Br-HIPS. With the increase of the pyrolysis temperature, the bromine content increased slightly. When the pyrolysis temperature was $550^{\circ} \mathrm{C}, 77.4 \mathrm{wt}$ \% of the total bromine in the Br-HIPS sample was transferred into the oil products. Furthermore, it should be mentioned that there are some solid precipitates existed in the oil phase. Because $\mathrm{Sb}_{2} \mathrm{O}_{3}$ might react with $\mathrm{HBr}$ derived from the thermal degradation of BFRs and then generate $\mathrm{SbBr}_{3}$ with a low boiling point, which easily evaporated from the reactor and condensed in the oil section, resulting in the high bromine contents in the oil products, as shown in Fig. 4. 
Table 3. Total bromine contents in the oil products derived from the pyrolysis of Br-HIPS at different temperatures.

\begin{tabular}{|c|c|c|c|}
\hline & $450^{\circ} \mathrm{C}$ & $500^{\circ} \mathrm{C}$ & $550^{\circ} \mathrm{C}$ \\
\hline $\mathrm{Br}$ in oil $(\text { wt. } \%)^{\mathrm{a}}$ & 7.96 & 8.21 & 8.56 \\
\hline Yield of bromine in the oil $(\%)^{\mathrm{b}}$ & 68.31 & 74.49 & 77.38 \\
\hline
\end{tabular}

${ }^{\mathrm{a}} \mathrm{Br}$ in oil (wt. \%) = mass of bromine in oil $(\mathrm{g}) /$ mass of oil $(\mathrm{g}) \times 100$;

${ }^{\mathrm{b}}$ Yield of $\mathrm{Br}(\%)=$ mass of $\mathrm{Br}$ in oil/ mass of $\mathrm{Br}$ in plastic $\times 100$.

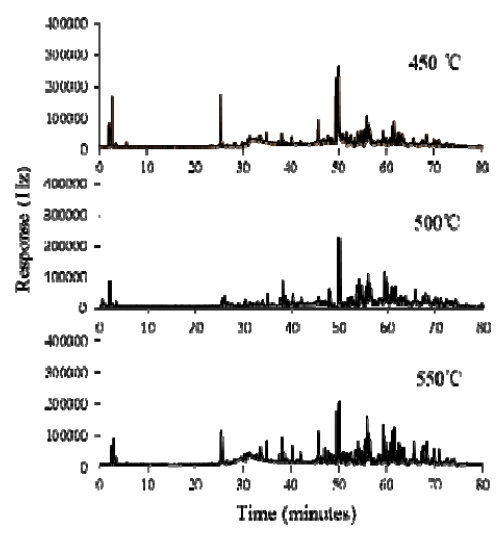

Fig. 6. GC-ECD chromatograms of the oils produced by the pyrolysis of Br-HIPS at different temperatures

The total bromine content in the oil products contained the organobrominated and inorganic brominated compounds, such as antimony bromide. As for the organobromine content in the pyrolysis oils, it was determined by the GC-ECD analysis, which only responds to organo-halogenated compounds, in terms of the organobrominated compounds in this study. In each analysis, the same volume of oils was injected and analyzed at the same GC conditions (Miskolczi, Hall, Angyal, Bartha \& Williams, 2008). Therefore, the chromatographs can be generally compared with each other to reveal the variation of the organobrominated compounds by the number, size and intensity of ECD peaks. Fig. 6 shows the results of the GC-ECD analysis of the oil products obtained at different pyrolysis temperatures. It apparently illustrated that a large amount of organobrominated compounds also existed in the pyrolysis oil. As the increase of the pyrolysis temperature, the intensity of the ECD peak increased, especially the peaks in the later retention time.

\subsection{Effect of Additives on the Pyrolysis of Br-HIPS}

\subsubsection{Effect of Additives on the Gas and Oil Products}

As stated above, a high total bromine content and lots of organobrominated compounds retained in the oil products, and the effect of the pyrolysis temperature on them was limited. Therefore, the effective catalysts or additives were essential for the debromination to obtain valuable oil products. RM, CL and NZ were industrial solid wastes or natural mineral. Because of their low-cost, high metal oxides content and catalytic cracking properties, they were frequently applied as catalysts or additives for the pyrolysis of biomass and plastics (Yathavan \& Agblevor, 2013; Lópeza et al, 2011; Lee, 2001; Zhang, Zhang, Yang \& Yan, 2014).

Table 4. Main components of gas and oil products (wt.\%/sample mass)

\begin{tabular}{lcccc}
\hline Main products & Thermal & $+\mathrm{RM}$ & $+\mathrm{CL}$ & $+\mathrm{NZ}$ \\
\hline Main gaeous components & & & & \\
Hydrogen & 0.02 & 0.00 & 0.00 & 0.05 \\
Methane & 0.15 & 0.29 & 0.16 & 0.27 \\
Ethene & 0.14 & 0.35 & 0.15 & 0.49 \\
Ethane & 0.16 & 0.43 & 0.18 & 0.60
\end{tabular}




\begin{tabular}{|c|c|c|c|c|}
\hline Propene & 0.21 & 0.49 & 0.22 & 0.64 \\
\hline Propane & 0.17 & 0.65 & 0.14 & 0.69 \\
\hline \multicolumn{5}{|l|}{ Main oil components } \\
\hline \multicolumn{5}{|l|}{ Single ring compounds } \\
\hline Toluene & 6.96 & 3.16 & 3.78 & 3.39 \\
\hline Ethylbenzene & 28.60 & 11.80 & 11.03 & 16.20 \\
\hline Styrene & 0.48 & 25.10 & 31.17 & 19.69 \\
\hline Cumene & 4.29 & 2.42 & 1.96 & 3.86 \\
\hline$\alpha$-Methylstyrene & 0.92 & 1.47 & 3.05 & 1.37 \\
\hline \multicolumn{5}{|l|}{ Two ring compounds } \\
\hline 1,3-Diphenylpropane & 18.02 & 8.98 & 6.93 & 11.43 \\
\hline 1,3-diphenyl-1-butene & 4.44 & 1.03 & 1.49 & 2.29 \\
\hline 2-Methylnaphthalene & 0.14 & 0.10 & 1.32 & 1.37 \\
\hline 1-Methyl-3-phenylindan & 0.47 & 1.86 & 0.79 & 2.60 \\
\hline \multicolumn{5}{|l|}{ Multi ring compounds } \\
\hline 2-Benzylnaphthalene & 0.92 & 1.19 & 0.89 & 1.41 \\
\hline Anthracene & n.d. ${ }^{\mathrm{a}}$ & 1.01 & 0.87 & 1.49 \\
\hline 9-Ethenylanthracene & 0.28 & 0.41 & 0.22 & 0.83 \\
\hline 1,3,5-Triphenylbenzene & 0.85 & 0.47 & 0.60 & 0.35 \\
\hline \multicolumn{5}{|l|}{ Brominated compounds } \\
\hline (1-Bromoethyl)benzene & 2.75 & 0.53 & 0.51 & 0.97 \\
\hline 3-Methylbenzyl bromide & 0.47 & n.d. & n.d. & 0.10 \\
\hline 9,10-Dibromoanthracene & 0.11 & 0.15 & 0.15 & 0.24 \\
\hline
\end{tabular}

${ }^{\mathrm{a}}$ Not detected.

In this study, in order to investigate the effect of RM, CL and NZ additives on the degradation of Br-HIPS and the debromination characteristic, the pyrolysis experiments were carried out in presence of each additive at the pyrolysis temperature of $500^{\circ} \mathrm{C}$. Because of the reaction of the additives and the evolved $\mathrm{HBr}$, the accurate mass balance and the product yields of Br-HIPS degradation were difficult to be calculated. As for the gaseous products, they were measured by the GC-TCD and the results were listed in Table 4 . It was found that when the Br-HIPS sample was pyrolyzed without additives, propene and propane were the main gaseous products. When CL was used in the reaction system, there was no obvious change in the gaseous product. When the Br-HIPS sample was pyrolyzed with RM and NZ, respectively, the yields of gaseous products increased significantly, especially in the case of NZ. It was presumably because of the zeolite property (acidity and large surface area) of RM and NZ, which could exert a catalytic cracking effect during the pyrolysis of Br-HIPS and promoted the gaseous products. In addition, the bromine content of the gas products was almost zero, regardless of the presence or absence of each additive. This result was consistent with the results reported by other researchers (Hall \& Williams, 2008).

The oil products evolved from the pyrolysis of Br-HIPS in the absence and presence of additives were analyzed by GC-MS, and the main components of them were also listed in Table 3. It illustrated that toluene, ethylbenzene, styrene and 1,3-diphenylpropane were the main components in oil products, over $50 \mathrm{wt} \%$ of Br-HIPS sample weight. It was in well agreement with the previous findings (Hall \& Williams, 2008; Miskolczi et al, 2008; Jung et al, 2012), which was a consequence of the structure property and the thermal degradation property of the HIPS matrix. In addition, in the case of without additives, the ethylbenzene, cumene and 1,3-diphenylpropane were the main components of the oil products while the small amount of styrene existed in the oil. It was attributed to the presence of $\mathrm{Sb}_{2} \mathrm{O}_{3}$ that reacted with $\mathrm{HBr}$ derived from the decomposition of BFRs to produce $\mathrm{SbBr}_{3}$ with an acidity nature, which played a catalytic role to convert the styrene and $\alpha$-methylstyrene into ethylbenzene and 


\section{1,3-diphenylpropane by the intermolecular $\mathrm{H}$ transfer and the intermolecular carbanion.}

However, when the additives were added, the yield of styrene increased a lot, accompanied by the decrease of ethylbenzene and 1,3-diphenylpropane. On the one hand, it partially originated from the fact that the main components of these three additives were metal oxides, such as $\mathrm{Fe}_{2} \mathrm{O}_{3}$ and $\mathrm{CaO}$, which would exert basic-catalytic impact on the degradation of HIPS to form carboanions by the $\mathrm{H}$ abstraction, resulting in the increase of styrene in the oil products (Lee et al, 2001). On the other hand, the existence of metal oxides in the additives would inhibit the formation of $\mathrm{SbBr}_{3}$ due to the competing reaction with $\mathrm{HBr}$ generated by the degradation of BFRs. In addition, owing to the pore property, the additives also could capture the produced volatile $\mathrm{SbBr}_{3}$, subsequently reducing its amount in the oil.

In addition, when the Br-HIPS sample was pyrolyzed in the presence of RM, CL and NZ, respectively, the amount of styrene in the oil products was obviously different. It was probably caused by the differences in the composition and the surface area of additives, as shown in Table 1. In the case of RM, it was mainly attributed to the fact that red mud also contained the $\mathrm{SiO}_{2}, \mathrm{Al}_{2} \mathrm{O}_{3}$ and $\mathrm{TiO}_{2}$ components and forms the Si-O-T units $(\mathrm{T}=\mathrm{Si}$ or $\mathrm{Al}$ ), which makes RM to have zeolite nature (Brønsted acid) and play catalytic action to increase the amount of ethybenzene by further hydrogenation of styrene (Wang, Ang \& Tadé, 2008). As for NZ, a high ratio of $\mathrm{Al}_{2} \mathrm{O}_{3}$ and $\mathrm{SiO}_{2}$ in NZ will also improve the acidity of NZ. Therefore, the oil derived from the pyrolysis of $\mathrm{Br}-\mathrm{HIPS}$ and NZ contained smaller amounts of styrene and larger amounts of ethylbenzene. Besides, the high amounts of 2-methylnaphthalene, anthracene and 9-ethenylanthracene compounds in the oil were detected due to the Diels-Alder reaction, which was proposed by Koo et al (1991). It also illustrated the stronger acidity of NZ than the other two additives.

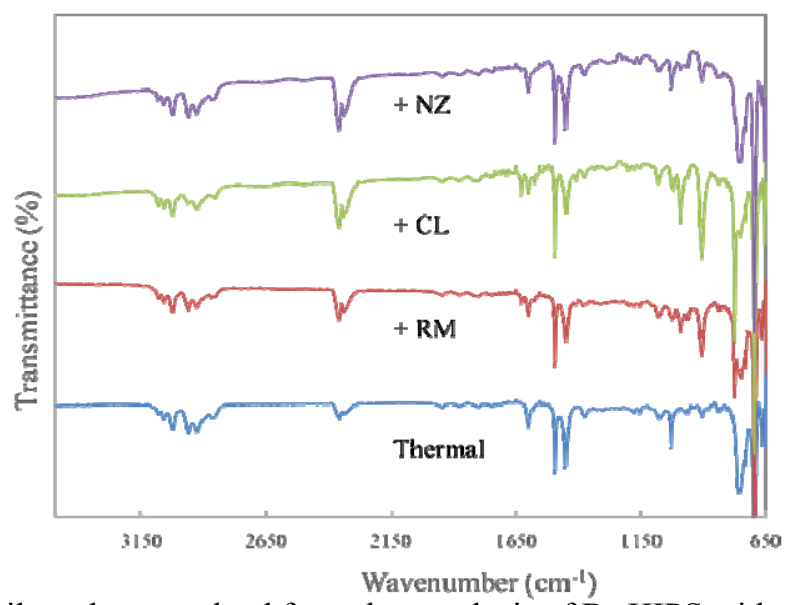

Fig. 7. FT-IR spectra of oil products evolved from the pyrolysis of Br-HIPS without additive, with RM, CL and $\mathrm{NZ}$ additives (thin film/ $\mathrm{KCl}$ )

For the purpose of verifying the molecular structure and the organic functional groups, the oil products were further characterized by FT-IR analysis and the result is presented in Fig. 7. Generally, the band in the 3150-3000 $\mathrm{cm}^{-1}$ range is associated with the vibration of $\mathrm{C}-\mathrm{H}$ bond in the aromatic ring. The strong bands observed in the interval of $900-675 \mathrm{~cm}^{-1}$ were assigned of $\mathrm{C}-\mathrm{H}$ out-of-plane vibration of the mono-substituted aromatic ring, which further confirmed the aromatic characteristics of the oil products. Additionally, the vibration bands in the region of 3000-2900 $\mathrm{cm}^{-1}$ correspond to the $\mathrm{C}-\mathrm{H}$ asymmetric stretching of $\mathrm{CH}_{3}, \mathrm{CH}_{2}$ and $\mathrm{CH}$ groups. The vibration bands at 992 and $906 \mathrm{~cm}^{-1}$ are the typical vibration mode of $\mathrm{CH}=\mathrm{CH}_{2}$ in the vinyl compounds and the bands at $1450 \mathrm{~cm}^{-1}$ are ascribed to the asymmetric bending vibration of ethyl groups. The aliphatic functional groups observed in the FTIR spectra are probably attributed to the alkyl groups attached to the aromatic rings.

Comparing the FTIR spectra of the oil products derived from Br-HIPS pyrolysis in the absence and presence of additives, it was observed that the vibration bands at 992 and $906 \mathrm{~cm}^{-1}$, corresponding to $\mathrm{CH}=\mathrm{CH}_{2}$ bonds in the vinyl compounds, in the oil from the Br-HIPS pyrolysis with additives are more intensive than that of oil from the Br-HIPS pyrolysis without additives. Whereas, the bands at $1450 \mathrm{~cm}^{-1}$ are ascribed to the asymmetric bending vibration of ethyl groups and become weaker than that when no additive was used. The above variations corroborated the GC-MS analytical results that when additives were used, the amount of ethylbenzene decreased, accompanied by the increase of styrene. In addition, it should be noted that the bond vibration bands at 1030 $\mathrm{cm}^{-1}$ were typical of aryl-bromines (Hall \& Williams, 2008; Miskolczi et al, 2008) and when the additives were 
used, the intensity of this band became weakened, which was also well associated with those obtained by the GC-MS analysis.

\subsubsection{Effect of Additives on Bromine and Antimony Contents in the Oil Products}

The total bromine and antimony contents in the pyrolysis oils were determined using a bomb calorimeter equipped with an ion chromatograph and ICP-MS after digestion of oil samples, respectively. The bromine and antimony contents of each oil product were listed in Table 5. It was apparent that the additives played a positive role in the removal of bromine and antimony contents from the pyrolysis oils. At the same pyrolysis temperature of $500^{\circ} \mathrm{C}$, the bromine content of $8.21 \mathrm{wt} . \%$ in the pyrolysis oil of Br-HIPS degradation without additives was reduced dramatically to $0.84 \mathrm{wt} . \%, 0.91 \mathrm{wt} . \%$ and $3.47 \mathrm{wt} . \%$, when RM, CL and NZ were used as the additive, respectively. RM was more effective than the other two additives in the respect of bromine removal, which was attributed to the fact that, on the one hand, $\mathrm{Fe}_{2} \mathrm{O}_{3}$ in the red mud would react with $\mathrm{HBr}$ derived from the degradation of BFRs and hinder the formation of volatile $\mathrm{SbBr}_{3}$, on the other hand, the zeolite property of RM (Lópeza et al, 2011) could catalytically degrade the organobromine compounds. The effect of NZ on the bromine removal was weakest. It was mainly due to the fact that $\mathrm{Al}_{2} \mathrm{O}_{3}$ and $\mathrm{SiO}_{2}$ were the main components, which could not react with bromine radicals derived from the degradation of BFRs. Therefore, it illustrated that the reaction between bromine and metal oxides was the dominant mechanism of the bromine fixation when the additives were used. In addition, the antimony content of the oil product was measured and the result is also shown in Table 5. When additives were employed, the antinomy content in the oils was also reduced a lot. The main reasons were already explained in the 3.3 .1 session.

Table 5. Total bromine and antimony contents in the oil products derived from the pyrolysis of Br-HIPS with and without additives at the temperature of $500^{\circ} \mathrm{C}$

\begin{tabular}{lcccc}
\hline & Thermal & $+\mathrm{RM}$ & $+\mathrm{CL}$ & $+\mathrm{NZ}$ \\
\hline Br in oil (wt. \%) & 8.21 & 0.84 & 0.91 & 3.47 \\
$\mathrm{Sb}$ in oil (wt. \%) & 1.84 & 0.35 & 0.52 & 0.69 \\
\hline
\end{tabular}

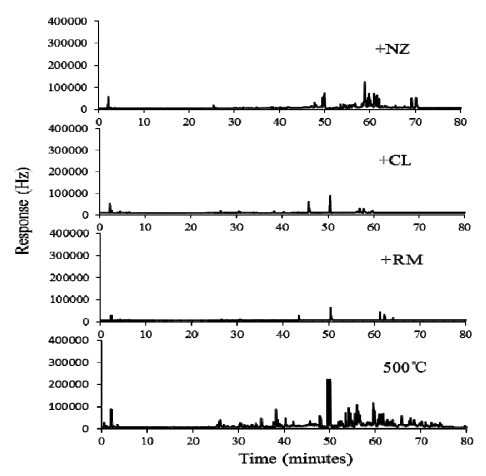

Fig. 8. GC-ECD chromatographs of the oils produced from the pyrolysis of Br-HIPS without and with additives at the temperature of $500^{\circ} \mathrm{C}$

The main purpose of using the additives was to remove the organobromine from the pyrolysis oils and obtained the clean oil products. The organobromine compounds in the oils were analyzed by the GC-ECD and the results are presented in Fig. 8. When the Br-HIPS sample was pyrolyzed with NZ, certain portion of the organobromine compounds still retained in the pyrolysis oil. Meanwhile, when RM and CL were applied, the intensity of ECD peaks apparently reduced dramatically. It implied that RM and CL could also effectively suppress the formation of organobrominated compounds and produce the valuable oil products. 


\subsubsection{Pyrolysis Residues}

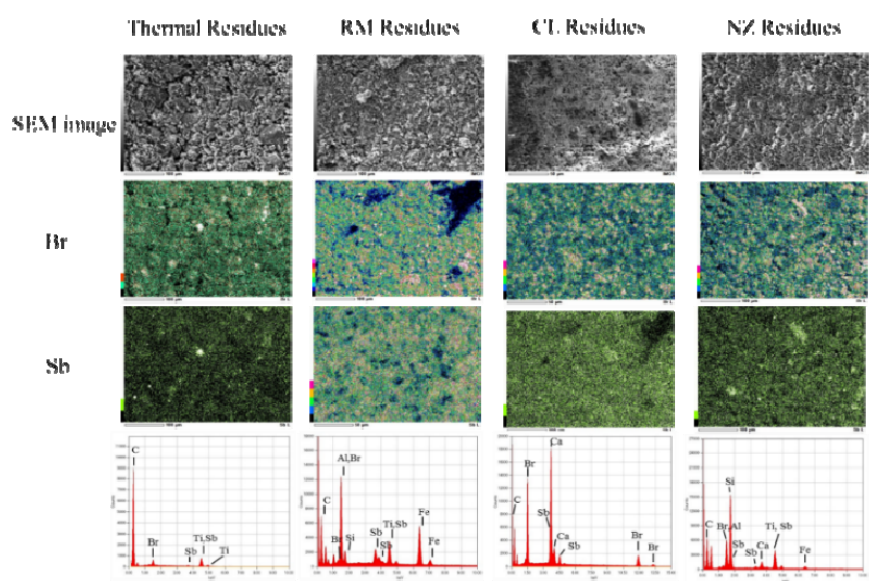

Fig. 9. SEM and EDX analysis of the residues derived from the pyrolysis of Br-HIPS sample without and with $\mathrm{RM}, \mathrm{CL}$ and NZ, respectively

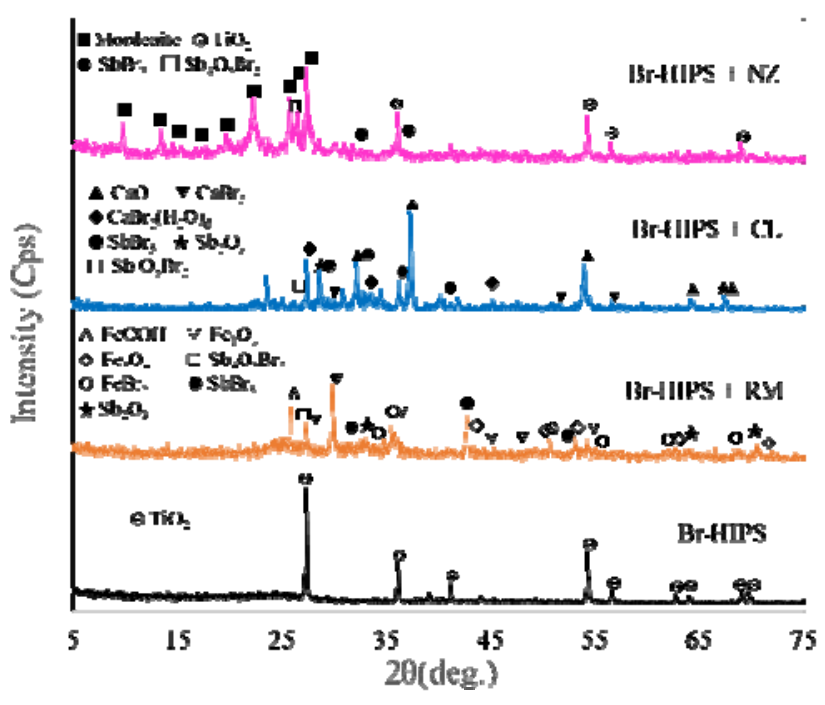

Fig. 10. XRD patterns of residues derived from the pyrolysis of Br-HIPS sample without and with RM, CL and $\mathrm{NZ}$, respectively

When the Br-HIPS sample was pyrolyzed in the presence of catalysts, both bromine and antimony contents in the oils decreased dramatically. The bromine in the flame retardants is converted to not only $\mathrm{HBr}$ and the brominated organic compounds but also metal bromides left in the residues. However, because of very heterogeneous and intermingled nature of the residues, it was impossible to take representative sampling to analyze precise contents of $\mathrm{Br}$ and $\mathrm{Sb}$ in the residues (Hall et al, 2008). Therefore, the residues were qualitatively analyzed by the SEM-EDAX and XRD in order to determine and compare the additive change, residue compositions and bromine and antimony distributions in the residues. The results are presented in Fig. 9 and Fig. 10, respectively. In the EDAX pattern, when Br-HIPS was pyrolyzed in the absence of additives, the residue was found to contain carbon, titanium, bromine and antimony. The carbon can be caused by char formation. Only few of bromine and antimony was left in the residues. And from the XRD pattern, neither $\mathrm{Sb}_{2} \mathrm{O}_{3}$ nor $\mathrm{SbBr}_{3}$ crystal was identified in the residues in Fig. 10, whilst only the $\mathrm{TiO}_{2}$ crystal was observed, which is commonly employed as an additive in plastics (Hall et al, 2008). It was attributed to the reaction between $\mathrm{Sb}_{2} \mathrm{O}_{3}$ with $\mathrm{HBr}$, derived from the BFRs decomposition, thereby generating the volatile $\mathrm{SbBr}_{3}(\mathrm{Rzyman}$, Grabda, Oleszek-Kudlak, Shibata \& Nakamura, 2010; Grause, Karakita, Kameda, Bhaskar \& Yoshioka, 2012). Therefore, major parts of antimony and bromine were found in the oil rather the char when Br-HIPS was pyrolyzed (Jakab et al, 2003; Jung et al, 2012). 
In the case of Br-HIPS and RM pyrolysis, there were lots of bromine and antimony elements were observed in the residues from the EDAX pattern. When compared with XRD pattern of RM in Fig. 2, the peaks of $\mathrm{Fe}_{2} \mathrm{O}_{3}$ and $\mathrm{FeOOH}$ disappeared or weakened while the additional peaks of $\mathrm{FeBr}_{2}, \mathrm{Sb}_{4} \mathrm{O}_{5} \mathrm{Br}_{2}, \mathrm{SbBr}_{3}$ and $\mathrm{Sb}_{2} \mathrm{O}_{3}$ were detected. $\mathrm{FeBr}_{3}$ was not identified in the residues, which owes to that $\mathrm{FeBr}_{3}$ decomposes above $200^{\circ} \mathrm{C}$ to form $\mathrm{Br}_{2}$ and $\mathrm{FeBr}_{2}$ (Bhaskar et al, 2003; Terakado et al, 2011; Terakado et al, 2013). In addition, it was found that certain amount of $\mathrm{Fe}_{2} \mathrm{O}_{3}$ was reduced into $\mathrm{Fe}_{3} \mathrm{O}_{4}$ by the hydrogenation reaction.

When Br-HIPS was pyrolyzed with CL, as shown in Fig. 9, lots of bromine and antimony were also detected in the residues. From the XRD pattern, it was found that the peaks of $\mathrm{CaO}$ became weaker while the new peaks of $\mathrm{CaBr}_{2}$ and $\mathrm{CaBr}_{2}\left(\mathrm{H}_{2} \mathrm{O}\right)_{6}$ were observed in the pattern. The existence of $\mathrm{CaBr}_{2}\left(\mathrm{H}_{2} \mathrm{O}\right)_{6}$ was attributed to the hygroscopic nature of $\mathrm{CaBr}_{2}$ (Terakado et al, 2011; Terakado et al, 2013). In addition, the $\mathrm{Sb}_{2} \mathrm{O}_{3}$ were detected, which further confirmed the presence of lots of antimony existing in the residues.

As for the residues of Br-HIPS and NZ pyrolysis, no reflection characteristic of metal bromides was presented in the XRD pattern, except for $\mathrm{SbBr}_{3}$ and $\mathrm{Sb}_{4} \mathrm{O}_{5} \mathrm{Br}_{2}$. It was related to the fact that natural zeolite is mainly composed of $\mathrm{SiO}_{2}$ and $\mathrm{Al}_{2} \mathrm{O}_{3}$, which would not react with evolved $\mathrm{HBr}$. The amount of other metal oxides, such as $\mathrm{CaO}$ and $\mathrm{Fe}_{2} \mathrm{O}_{3}$, is few in $\mathrm{NZ}$ and then produced metal bromide species with too small particle sizes on the surface of the residue to be identified by the XRD method. As for NZ, the fixation of bromine and antimony was mainly associated with the physical adsorption of $\mathrm{SbBr}_{3}$ and $\mathrm{Sb}_{4} \mathrm{O}_{5} \mathrm{Br}_{2}$ on the surface of $\mathrm{NZ}$ (Hall et al, 2008). When compared with that of RM and CL, the bromine fixation ability of NZ was weaker and then the bromine and antimony content in the oils were relatively higher.

\section{Conclusion}

In this study, the pyrolysis of high impact polystyrene containing BFRs and $\mathrm{Sb}_{2} \mathrm{O}_{3}$ was carried out in the absence and presence of three additives (red mud, calcined limestone and natural zeolite) in a fixed bed reactor. In the pyrolysis of Br-HIPS without additives, with the increase of the pyrolysis temperature from $450^{\circ} \mathrm{C}$ to $550^{\circ} \mathrm{C}$, the yield of the residue decreased while the yield of the gas increased slightly. The yield of the oil product was dependent upon the pyrolysis temperature, and the maximum oil yield (84.4 wt.\%) was obtained at the pyrolysis temperature of $500^{\circ} \mathrm{C}$. In the pyrolysis of Br-HIPS with the additives, it was found that red mud and natural zeolite could increase the yield of the gaseous product because of their zeolite property. In addition, the use of additives, especially red mud and calcined limestone, could increase the amount of styrene at the expense of ethylbenzene and 1,3-diphenylpropane. Furthermore, the additives could also upgrade the oil products by reducing the total bromine content, organobrominated compounds and antimony content in the oil products significantly. Red mud was the most effective additives used in this study. Because, on the one hand, red mud played a cracking catalyst effect on destroying the organobrominated compounds. On the other hand, it could work as a sorbent to fix $\mathrm{HBr}$ formed by the Br-HIPS degradation. The bromine fixation abilities of red mud and calcined limestone were similar with each other and better than that of natural zeolite, which implied that the reaction between bromine and metal oxides was the dominant mechanism of the bromine fixation. Additionally, from the XRD and SEM-EDAX analysis of the residues, it was found that there were lots of metal bromides compounds existing in the residues, which further confirmed the above bromine fixation mechanism.

\section{Acknowledgement}

The authors would like to thank Dr. Tohru Kamo of Advanced Industrial Science and Technology (AIST), Tsukuba, Japan for his valuable help and discussion.

\section{References}

Aguado, J., Serrano, D. P., Miguel, G. S., Castro, M. C., \& Madrid, S. (2007). Feedstock recycling of polyethylene in a two-step thermo-catalytic reaction system. Journal of Analytical and Applied Pyrolysis, 79, 415-423. http://dx.doi.org/10.1016/j.jaap.2006.11.008

Ali, S., Garforth, A. A., Harris, D. H., Rawlence, D. J., \& Uemichi, Y. (2002). Polymer waste recycling over "used" catalysts. Catalysis Today, 75, 247-255. http://dx.doi.10.1016/S0920-5861(02)00076-7

Álvarez, J., Ordóñez, S., Rosal, R., Sastre, H. V., \& Díez, F. V. (1999). A new method for enhancing the performance of red mud as a hydrogenation catalyst. Applied Catalysis A: General, 180, 399-409. http://dx.doi.10.1016/S0926-860X(98)00373-1

Bhaskar, T., Matsui, T., Uddin, M., A., Kaneko, J., Mutoa, A., \& Sakata, Y. (2003). Effect of Sb2O3 in brominated heating impact polystyrene (HIPS-Br) on thermal degradation and debromination by iron oxide carbon composite catalyst (Fe-C). Applied Catalysis B: Environmental, 43, 229-241. http://dx.doi.10.1016/S0926-3373(02)00306-5 
Blazsó, M., \& Czégény, Z. (2006). Catalytic destruction of brominated aromatic compounds studied in a catalyst microbed coupled to gas chromatography/mass spectrometry. Journal of Chromatography A, 1130, 91-96. http://dx.doi.10.1016/j.chroma.2006.05.009

Bozi, J., \& Blazsó, M. (2009). Catalytic modification of pyrolysis products of nitrogen-containing polymers over Y zeolites. Green Chemistry, 11, 1638-1645. http://dx.doi.10.1039/b913894n

Cardona, S., C., \& Corma, A. (2000). Tertiary recycling of polypropylene by catalytic cracking in a semibatch stirred reactor Use of spent equilibrium FCC commercial catalyst. Applied Catalysis B: Environmental, 25, 151-162. http://dx.doi.10.1016/S0926-3373(99)00127-7

Grause, G., Karakita, D., Kameda, T., Bhaskar, T., \& Yoshioka, T. (2012). Effect of heating rate on the pyrolysis of high-impact polystyrene containing brominated flame retardants: Fate of brominated flame retardants. Journal of Material Cycles and Waste Management, 14, 259-265. http://dx.doi.10.1007/s10163-012-0067-8

Hall, W., \& Williams, P. T. (2008). Removal of organobromine compounds from the pyrolysis oils of flame retarded plastics using zeolite catalysts. Journal of Analytical and Applied Pyrolysis, 81, 139-147. http://dx.doi.10.1016/j.jaap.2007.09.008

Hall, W., J., Miskolczi, N., Onwudili, J., \& Williams, P., T. (2008). Thermal Processing of Toxic Flame-Retarded Polymers Using a Waste Fluidized Catalytic Cracker (FCC) Catalyst. Energy \& Fuels, 22, 1691-1697. http://dx.doi.10.1021/ef800043g

Hinz, B., Hoffmockel, M., Pohlmann, K., Schädel, S., Schimmel, I., \& Sinn, H. (1994). Dehalogenation of pyrolysis products. Journal of Analytical and Applied Pyrolysis, 30, 35-46. http://dx.doi.10.1016/0165-2370(94)00800-0

Jakab, E., Uddin, M. A., Bhaskar, T., \& Sakata, Y. (2003). Thermal decomposition of flame-retarded high-impact polystyrene. Journal of Analytical and Applied Pyrolysis, 68-69, 83-89. http://dx.doi.10.1016/S0165-2370(03)00075-5

Jung, S. H., Kim, S. J., \& Kim, J. S. (2012). Fast pyrolysis of a waste fraction of high impact polystyrene (HIPS) containing brominated flame retardants in a fluidized bed reactor: The effects of various Ca-based additives $\left(\mathrm{CaO}, \mathrm{Ca}(\mathrm{OH})_{2}\right.$ and oyster shells) on the removal of bromine. Fuel, 95, 514-520. http://dx.doi.10.1016/j.fuel.2011.11.048

Koo, J. K., Kim, S. W., \& Seo, Y. H. (1991). Characterization of aromatic hydrocarbon formation from pyrolysis of polyethylene-polystyrene mixtures. Resources, Conservation and Recycling, 5, 365-382. http://dx.doi.10.1016/0921-3449(91)90013-E

Lee, S. Y., Yoon, J. H., Kim, J. R., \& Park, D. W. (2001). Catalytic degradation of polystyrene over natural clinoptilolite zeolite. Polymer Degradation and Stability, 74, 297-305. http://dx.doi.10.1016/S0141-3910(01)00162-8

Lee, S. Y., Yoon, J. H., Kim, J. R., \& Park, D. W. (2002). Degradation of polystyrene using clinoptilolite catalysts. Journal of Analytical and Applied Pyrolysis, 64, 71-83. http://dx.doi.10.1016/S0165-2370(01)00171-1

Lópeza, A., Marco, I. D., Caballeroa, B. M., Laresgoiti, M. F., Adrados, A., \& Aranzabal, A. (2011). Catalytic pyrolysis of plastic wastes with two different types of catalysts: ZSM-5 zeolite and Red Mud. Applied Catalysis B: Environmental, 104, 211-219. http://dx.doi.10.1016/j.apcatb.2011.03.030

Miskolczi, N., Hall, W. J., Angyal, A., Bartha, L., \& Williams, P. T. (2008). Production of oil with low organobromine content from the pyrolysis of flame retarded HIPS and ABS plastics. Journal of Analytical and Applied Pyrolysis, 83, 115-123. http://dx.doi.10.1016/j.jaap.2008.06.010

Ni, M. J., Xiao, H. X., Chi, Y., Yan, J. H., Buekens, A., Jin, Y. Q., \& Lu, S. Y. (2012). Combustion and inorganic bromine emission of waste printed circuit boards in a high temperature furnace. Waste Management, 32, 568-574. http://dx.doi.10.1016/j.wasman.2011.10.016

Ongondo, F. O., Williams, I. D., \& Cherrett, T. J. (2011). How are WEEE doing? A global review of the management of electrical and electronic wastes. Waste Management, 31, 714-730. http://dx.doi.10.1016/j.wasman.2010.10.023

Ordóñez, S., Sastre, H., \& Deíz, F. V. (2001). Characterisation and deactivation studies of sulfided red mud used as catalyst for the hydrodechlorination of tetrachloroethylene. Applied Catalysis B: Environmental, 29, 263-273. http://dx.doi.org/10.1016/S0926-3373(00)00207-1 
Park, E. S., Kang, B. S., \& Kim, J. S. (2008). Recovery of Oils with High Caloric Value and Low Contaminant Content by Pyrolysis of Digested and Dried Sewage Sludge Containing Polymer Flocculants. Energy \& Fuels, 22, 1335-1340. http://dx.doi.10.1021/ef700586d

Rzyman, M., Grabda, M., Oleszek-Kudlak, S., Shibata, E., \& Nakamura, T. (2010). Studies on bromination and evaporation of antimony oxide during thermal treatment of tetrabromobisphenol A (TBBPA). Journal of Analytical and Applied Pyrolysis, 88, 14-21. http://dx.doi.10.1016/j.jaap.2010.02.004

Sushil, S., \& Batra, V. S. (2008). Catalytic applications of red mud, an aluminium industry waste: A review. Applied Catalysis B: Environmental, 81, 64-77. http://dx.doi.10.1016/j.apcatb.2007.12.002

Syamsiro, M., Wu, H., Komoto, S., Cheng, S., Noviasri, P., Prawisudha, P., \& Yoshikawa, K. (2013). Co-Production of Liquid and Gaseous Fuels from Polyethylene and Polystyrene in a Continuous Sequential Pyrolysis and Catalytic Reforming System. Energy and Environment Research, 3, 2. http://dx.doi.org/10.5539/eer.v3n2p90

Terakado, O., Ohhashi, R., \& Hirasawa, M. (2011). Thermal degradation study of tetrabromobisphenol A under the presence metal oxide: Comparison of bromine fixation ability. Journal of Analytical and Applied Pyrolysis, 91, 303-309. http://dx.doi.10.1016/j.jaap.2011.03.006

Terakado, O., Ohhashi, R., \& Hirasawa, M. (2013). Bromine fixation by metal oxide in pyrolysis of printed circuit board containing brominated flame retardant. Journal of Analytical and Applied Pyrolysis, 103, 216-221. http://dx.doi.org/10.1016/j.jaap.2012.10.022

United Nations Environment Programme [UNEP]. (2009). Retrieved from http://www.unep.org/yearbook/2009/

Vasile, C., Brebu, M., A., Totolin, M., Yanik, J., Karayildirim, T., \& Darie, H. (2008). Feedstock Recycling from the Printed Circuit Boards of Used Computers. Energy \& Fuels, 22, 1658-1665. http://dx.doi.10.1021/ef700659t

Wang, S. B., Ang, H. M., \& Tadé, M. O. (2008). Novel applications of red mud as coagulant, adsorbent and catalyst for environmentally benign processes. Chemosphere, 72, 1621-1635. http://dx.doi.10.1016/j.chemosphere.2008.05.013

Yang, X. N., Sun, L. S., Xiang, J., Hu, H., \& Su, S. (2013). Pyrolysis and dehalogenation of plastics from waste electrical and electronic equipment (WEEE): A review. Waste Management, 33, 462-473. http://dx.doi.org/10.1016/j.wasman.2012.07.025

Yanik, J., Uddin, M. A., Ikeuchi, K., \& Sakata, Y. (2001). The catalytic effect of Red Mud on the degradation of poly (vinyl chloride) containing polymer mixture into fuel oil. Polymer Degradation and Stability, 73, 335-346. http://dx.doi.10.1016/S0141-3910(01)00095-7

Yathavan, B. K., \& Agblevor, F. A. (2013). Catalytic Pyrolysis of Pinyon-Juniper Using Red Mud and HZSM-5. Energy \& Fuels, 27, 6858-6865. http://dx.doi.org/10.1021/ef401853a

Zhang, L., Zhang, B., Yang, Z. Q., \& Yan, Y. F. (2014). Pyrolysis behavior of biomass with different Ca-based additives. RSC Advances, 4, 39145-391555. http://dx.doi.10.1039/c4ra04865b

\section{Copyrights}

Copyright for this article is retained by the author(s), with first publication rights granted to the journal.

This is an open-access article distributed under the terms and conditions of the Creative Commons Attribution license (http://creativecommons.org/licenses/by/3.0/). 